\title{
DERECHOS TERRITORIALES: \\ EL CASO DE LA FAMILIA HITO RANGI
}

Oscar Vargas Fuentes 


\section{OSVAR VARGAS FUENTES}

Abogado de la Universidad Nacional Andrés Bello. Ex Fiscal adjunto y jefe de la Fiscalía local de Freirina 2001-2003 y ex Fiscal adjunto y jefe de la Fiscalía local de Isla de Pascua 2003-2008. Actual abogado defensor del Clan Hito Rangi. 


\section{DERECHOS TERRITORIALES: EL CASO DE LA FAMILIA HITO RANGI}

El presente artículo es fruto de mi experiencia laboral en la Isla de Pascua, donde viajé enviado como jefe de la Fiscalía local el año 2003. Como sabemos, esta pequeña isla, que puede ser cruzada en menos de una hora en automóvil y que además es la más lejana a cualquier otro pedazo de tierra en el mundo, ha sido por mucho tiempo desdibujada en relatos turísticos-publicitarios y percibida de manera estereotipada y folklórica en el continente. Políticas de gobierno y de agencias que nos muestran un paraíso rescatado de la barbarie y la colonización son una pared que oculta las luchas históricas de este pueblo. En mi trabajo como fiscal, cargo en el que estuve hasta el año 2008, fui conociendo al pueblo rapanui, descubriendo en él, así como lo han hecho muchos de sus habitantes, una nación. Mi compromiso con los temas cruciales de Isla de Pascua me han llevado -luego de dejar el cargo de fiscal- a actuar como el abogado defensor del clan Hito Rangi en la disputa por las tierras en las que se asienta el hotel Hana Roa. Es en base a estas vivencias que escribo este texto, con el fin de aportar al conocimiento de un litigio específico, porque a través de él es posible encontrar las huellas de las demandas históricas de un pueblo.

¿Qué duda cabe que el conflicto de Rapa Nui -el cual se ha visto acentuado durante el último lustro-, obedece no solo a la inexistencia de políticas públicas destinadas a reconocer de una manera palpable y concreta los derechos de índole colectivo que asisten a dicho pueblo -tales como libre determinación, autogobierno y derechos territoriales-, sino que, de igual manera, y lo que es peor, al irrespeto por parte de nuestra nación al tratado que invocamos como título de la soberanía que nuestro Estado ejerce sobre los territorios del pueblo de Rapa Nui? Un tratado, también denominado "Acuerdo de Voluntades", cuya no ratificación por parte de Chile forma parte de la violación sistemática de las propias normas que nuestro Estado generó para mantener en manos del pueblo rapanui los territorios que ancestralmente ocupan los descendientes de aquella primera migración liderada por el 'ariki Hotu Matu'a. ¿Qué duda cabe del arrebato de lo más sagrado, entendiendo como sustrato de supervivencia de dicho pueblo el apego o vinculación con su tierra, la cual es la base, no solamente de su supervivencia económica, sino que también de su vida espiritual y cultural? A este respecto, no resulta baladí que tanto el pueblo como sus territorios ancestrales se amalgamen en un solo concepto: Rapa Nui.

En tal sentido, en ese tratado, sui generis y suscrito por una parte que no sabía leer ni escribir el español, se reconocía el dominio o propiedad de los territorios comprendidos dentro de Rapa Nui para sus originarios. Ello, sin embargo, no impidió que fuera abiertamente quebrantado en el año 1933 por la otra parte, esto es, por el Estado chileno. Este, en aras de resguardar dicha posesión insular de las compañías explotadoras de ganado, cuyas libertades él mismo había tolerado y fomentado mediante ridículos cánones 
de arrendamientos o concesiones -las que además incluían sistemas de servidumbres institucionalizados-, inscribió a su nombre dichos territorios el día 11 de noviembre del mencionado año. Ello se hizo en virtud de la regla consagrada en el Art. 590 de nuestro Código Civil, el cual prescribe que son bienes del Estado todas las tierras que, estando situadas dentro de los límites territoriales, carecen de otro dueño; esta inscripción se materializó en el Conservador de Bienes Raíces de Valparaíso.

Parece pertinente citar esta inscripción debido a su extraordinaria simpleza e insospechadas implicancias. Entre muchas de ellas, el conflicto que hoy enfrenta al denominado Clan Hito Rangi con los operadores del Hotel Hana Roa. La inscripción reza:

"El Fisco, es dueño de la Isla de Pascua, denominada también Rapa Nui ubicada en

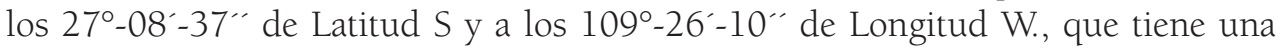
superficie de quince mil seiscientos noventa y siete hectáreas y que deslinda por el Norte, Sur, Oriente y Poniente con el Océano Pacífico. Adquirió dicha isla por ocupación en virtud del artículo quinientos noventa del Código Civil y en conformidad a lo ordenado por auto del Primer Juzgado Civil de Mayor Cuantía de esta ciudad (Valparaíso)".

Es este primer acto conservatorio está inspirado en el artículo que don Andrés Bello redactó y también en su ilustre prosa. Es el que constituyó, de una manera formal, al Estado Chileno en propietario del Ombligo del Mundo o Te Pito o Te Henua. Este acto es completamente ajeno a las concepciones jurídico-culturales del pueblo rapanui en ese período y a su capacidad fáctica para oponerse al mismo por falta de conocimiento y por razones geográficas obvias. Esa inscripción, al mismo tiempo, se constituyó como cimiento de las sucesivas usurpaciones de que ha sido objeto dicho pueblo, cuyas acciones reinvindicativas, por otro lado, son criminalizadas por un Estado que, ya entrada la segunda década del siglo XXI, no quiso reconocer, por medio de políticas públicas reales, la tremenda deuda histórica con rapanui.

Ciertamente, esta deuda ha sido reconocida al suscribir tratados internacionales que imponen obligaciones a nuestro Estado, y que se traducen en límites de nuestra soberanía, en especial el Convenio 169 OIT (ratificado, vigente y vinculante) y la Declaración de las Naciones Unidas sobre los Derechos de los Pueblos Indígenas, normas que establecen una serie de reglas relacionadas con la propiedad:

1. Art. 13 (Convenio 169 OIT). Que los estados deben respetar la importancia especial que para los pueblos indígenas tiene la tierra y el territorio, entendidos como la totalidad del hábitat de las regiones que los pueblos indígenas ocupan o utilizan de alguna otra manera.

2. Art. 14.1. (Convenio 169 OIT) Debe reconocerse el derecho de propiedad y posesión que les corresponde sobre las tierras que tradicionalmente ocupan y debe garantizarse la posibilidad de utilizar las tierras a las que históricamente han tenido acceso, aunque no estén exclusivamente ocupadas por ellos. 
3. Art. 26.1 (Declaración) El Derecho de los Pueblos Indígenas a las tierras, territorios y recursos que tradicionalmente han poseído, ocupado o de otra forma utilizado o adquirido, incluyendo de esta manera no solo las que tradicionalmente ocupan si no también respecto de aquellas que han sido desposeídos ilegítimamente.

4. Art. 28 (Declaración) Derecho a la reparación, por medios que pueden incluir la restitución o, cuando ello no sea posible, una indemnización justa, imparcial y equitativa, por las tierras, los territorios y los recursos que tradicionalmente hayan poseído u ocupado o utilizado de otra forma y que hayan sido confiscados, tomados, ocupados, utilizados o dañados sin su consentimiento libre, previo e informado.

Las referidas normas supranacionales tienen efecto vinculante, dado que nuestra matriz constitucional establece en su Art. 5 que la soberanía radica en la Nación y que es ejercida por el pueblo a través de los plebiscitos y elecciones periódicas, además de las autoridades establecidas por ella, agregando en su inciso segundo que el ejercicio de la misma está limitado por el respeto a los derechos esenciales que emanan de la naturaleza humana.

Asimismo, se señala que es deber de los órganos del Estado respetar y promover tales derechos garantizados por la Constitución, así como por los tratados internacionales ratificados por Chile que se encuentren vigentes. De esta manera, el accionar legítimo del Estado, comprendiendo sus instituciones y autoridades, está limitado por los derechos esenciales que emanan de la naturaleza humana, los cuales deben además ser promovidos por estos. Entre estos derechos, en carácter de colectivo, se encuentran los ya mencionados.

Ahora bien, resulta paradójico que la inscripción conservatoria por la cual nuestro Estado se arroga, como propietario de los territorios de Rapa Nui, sea el instrumento que hoy en día sirve para despojarlos del legítimo derecho que les asiste respecto de sus territorios, pues ella misma obedeció en su oportunidad al interés de proteger los títulos que asistían a sus originarios respecto de la Compañía Explotadora de Isla de Pascua, la que, a su vez, se atribuía, en perjuicio de estos, el dominio de la mayor parte del territorio insular. Esto, descontextualizó la génesis y razón de ser de dicha inscripción.

Esta violación sistemática de derechos se ha plasmado en diversas decisiones adoptadas por la autoridad administrativa, la cual, hasta la tramitación de la Ley $\mathrm{N}^{\circ} 16.441$ (conocida coloquialmente como Ley Pascua), no permitió la aplicación del fuero común en los territorios de ultramar, transformándose dicha ínsula en un territorio ocupado, en el cual, a diferencia de lo que ocurría en el continente, no existían autoridades -a excepción de la Armada de Chile-, que permitiesen a al pueblo rapanui ejercer de manera básica los derechos que la Constitución y las leyes nacionales conferían a cualquier habitante de la República.

En este orden de ideas, es menester señalar que no fue sino hasta el año 1966 que con dicha ley se constituyeron los servicios públicos en Rapa Nui y se efectuaron los primeros actos de jurisdicción común en la isla; además, se consagró así el principio en 
que se cimentó, según el propio Policarpo Toro ${ }^{1}$, esta anuencia de voluntades plasmada en el ya referido acuerdo, a saber: el derecho inalienable e imprescriptible del pueblo de Rapa Nui sobre los territorios que ancestralmente han ocupado. En efecto, el Art. 38 de aquella ley reza:

"Art. 38: Facúltase al Presidente de la República para otorgar a personas naturales chilenas títulos de dominio en los territorios fiscales urbanos de la Isla de Pascua en conformidad a las normas contenidas en el decreto reglamentario 2.354, de 19 de mayo de 1933, del Ministerio de Tierras y Colonización, publicado en el 'Diario Oficial' de 23 de junio de 1933.

El otorgamiento por el Presidente de la República de títulos de dominio sobre tierras fiscales rurales en el departamento de Isla de Pascua se regirá por el decreto con fuerza de ley 65, de 1960, y sus modificaciones posteriores, en lo que le fueren aplicable, de acuerdo con la naturaleza y la ubicación de los terrenos.

El Presidente de la República, dentro del plazo de ciento veinte días, contado desde la fecha de esta ley, procederá a establecer por decreto supremo la ubicación y extensión de los terrenos a los cuales se aplicará lo establecido en el inciso anterior.

Los terrenos fiscales de Isla de Pascua que no se encuentren comprendidos en los incisos anteriores solo podrán entregarse en concesión de explotación a la Corporación de Fomento de la Producción o a alguna de sus empresas o sociedades filiales, a instituciones fiscales, semifiscales y de administración autónoma, a empresas o entidades en que tenga intervención el Fisco por aporte de capital y a los servicios de utilidad pública.

Dentro del plazo de ciento veinte días el Presidente de la República determinará las disposiciones del decreto con fuerza de ley 65, de 1960, y del decreto reglamentario 2.354, de 1933, que se aplicarán en el departamento de Isla de Pascua. Dentro del plazo señalado, podrá, además establecer el procedimiento para el otorgamiento de títulos".

Señalo lo anterior dado que el legislador del año 1966 tuvo como objetivo, al dictar la ley, el atar indisolublemente el destino de la propiedad de los terrenos ancestrales de Rapa Nui al de su pueblo, asegurándose con ello la subsistencia de una cultura única. Esta cultura se ve nuevamente amenazada por intereses económicos que, por medio de promesas de inversión y falso progreso, intentan desmembrar los territorios que por siempre han ocupado los descendientes del rey Hotu Matúa.

Este es el dilema respecto del cual nuestras instituciones administrativas y judiciales deberán pronunciarse prontamente, por lo cual, también, deberán optar acatando el reconocimiento del principio de inalienabilidad e imprescriptibilidad de la propiedad Rapa Nui, o aceptar que, mediante engaños como jabones y espejos, las personas que no forman parte del referido pueblo dobleguen la voluntad del Estado Chileno expresada

1. Policarpo Toro (1856-1921): marino chileno que incorporó la Isla de Pascua al Estado chileno en 1888. (N. del E.) 
en la ya citada Ley 16.441, apropiándose subrepticiamente de tierras pertenecientes a dicha nación. Esta última alternativa, de ser enarbolada por dichos órganos nos llevaría, no sin razón, a sostener que la propiedad de las tierras emplazadas en Isla de Pascua son susceptibles de apropiación por cualquier ciudadano que habite la República, dado que el conjunto de normas aplicable a la enajenación de dichos inmuebles en nada ha variado desde aquella época.

Esperamos con ansia que se produzca dicha discusión, pues el problema que enfrenta actualmente al clan Hito Rangi con los operadoras del denominado Hotel Hana Roa nunca ha llegado a instancias judiciales que diriman el quid del asunto, esto es: quién es el verdadero dueño de los terrenos donde se encuentra emplazado dicho complejo hotelero. Así, la discusión de fondo que se producirá zanjará de una vez por todas la mayor encrucijada que nuestra nación afronta desde una perspectiva geopolítica y de integración territorial, la cual no ha sido reconocida a cabalidad por nuestro Estado en las negociaciones que intenta sostener con los diversos clanes o familias rapanui; conversaciones en las que nunca se ha develado, al menos por parte del Estado, el tremendo interés que desde esta perspectiva geopolítica representa para nuestra nación Isla de Pascua.

Para comprender lo anterior, debemos recordar que la referida ínsula se encuentra emplazada donde finaliza la influencia asiática en el Pacífico Sur, en especial la china y japonesa, lo que al mismo tiempo nos permite señalar que Chile no limita al Oeste con el Océano Pacífico sino, entre otros, con Francia y Reino Unido, y al Norte con EE.UU. (Tahiti, Islas Pitcairn, Hawái), dado que Isla de Pascua -también conocida como Isla del Este o Easter Island- se constituye como el vértice Este del denominado Triángulo Polinésico, constituido además por Nueva Zalanda y Hawái. Lo anterior sin perjuicio de los territorios marítimos que Chile controla bajo dicha posesión insular.

De este modo, las decisiones que se adopten comprometen a todo el pueblo chileno, el cual está siendo observado con lupa por la Comunidad Internacional, la que a su vez, al igual que nuestra nación, se ha visto consternada por la militarización de que ha sido objeto Rapa Nui desde que comenzaron las reinvidicaciones territoriales de su pueblo. No se han desvanecido de la retina global la violencia policíaca ejercida por las autoridades administrativas, que amparándose en normas especiales lograron evitar los controles jurisdiccionales al ordenar el desalojo del denominado Centro Cívico de Hana Roa, sin pasar por el cedazo judicial (como en los viejos tiempos), violencia que se tradujo en la utilización de armas de fuego para desocupar inmuebles que son utilizados por diversos servicios públicos e instituciones del Estado emplazadas en Isla de Pascua. Estos servicios, desde una perspectiva de Derecho Internacional, constituyen Territorios Indígenas, respecto de los cuales Chile se alza como propietario en virtud de un título de dominio que tiene su génesis, como ya se expresó, en la Inscripción de las tierras de Isla de Pascua a nombre del Estado de Chile en 1933. Esto constituye un acto de usurpación al pueblo originario rapanui, encontrándose el Estado chileno en la obligación de restitución de dichas tierras La situación ha sido reconocida por el Estado chileno, que ha intentado remediar sin resultados mediante las cesiones relatadas, del Decreto Ley 2.885 y del Art. 69 de la Ley Indígena, que autorizan transferencias en dominio a título "gratuito" de tierras fiscales a originarios rapanui. 
Me hace sentido, a este respecto, la historia que me contó un gran amigo "continental" radicado desde la década de los 60 en la isla, en orden a lo que escuchó de una nua (anciana rapanui), quien al ser informada por un alto funcionario de gobierno que arribó a Isla de Pascua de que sería compensada con terrenos por el despojo que había sufrido de los que pertenecían a sus ascendientes, le inquirió de vuelta si traía tierra en sus maletas, dado que, según entendía ella, todo la tierra que comprende Rapa Nui es justamente de su pueblo. Es decir, desde su lógica y visión, absolutamente válida si adscribimos a un Derecho Internacional tutelar de los Derechos Humanos Colectivos, lo que pretendía dicho funcionario era compensarla de un despojo con tierras que también habían sido objeto de una usurpación a sus ancestros.

En relación a los terrenos en que se ubica el Hotel Hana Roa, la cuestión se complejiza aun más, dado que este se emplaza en terrenos que la propia Armada de Chile reconoció como de propiedad de la familia Hito antes de la inscripción del año 1933. De forma que en dichos terrenos -a mediados de la década del 60 del siglo pasado, con el advenimiento del turismo que nace de la mano de los primeros vuelos comerciales a Isla de Pascua por parte de LAN Chile-, el Estado decide construir una hostería estatal en los terrenos de la familia, en donde además se permitía acampar a extranjeros.

En el año 1970 doña Verónica Atamu Pakomio, viuda de Ricardo Hito Tepihe, sucesor ancestral de Napoleón Tepihe -a quien se le entregaron las tierras a mayor cabida, en los años 40- realiza una Cesión de Derechos Eventuales de 6.7 hectáreas a la CORFO para la construcción de dicha hostería. Esto fue de carácter estatal, lo que en ningún caso para ella significaba que se trataría de una situación irreversible, dado que en su concepto el término "eventual" implicaba que no era una situación definitiva, mucho menos perpetua; más bien implicaba una estado transitorio que obedecía a una situación de hecho que permitía que los visitantes pudiesen llevarse una buena impresión de este naciente destino turístico. En cuanto a lo anterior, sin perjuicio de que las fuentes a que he tenido acceso, me han señalado que la Sra. Atamu Pakomio no sabía leer y escribir cuando realizó la Cesión, por lo que poco puede desprenderse de este particular documento. Se trata de la única cesión efectuada por un miembro del pueblo rapanui al Estado chileno, y no viceversa, lo que sin lugar a dudas constituye un segundo reconocimiento expreso por parte de nuestro Estado de la propiedad o dominio ancestral de los territorios de la Familia Hito.

Con posterioridad a ello, el día 31 de octubre de 1970 el Fisco de Chile, amparado en la inscripción de dominio del año 1933, dona a CORFO por intermedio de su filial Hotelera Nacional S.A. (HONSA) el terreno que había cedido la nua Verónica; ello en flagrante contravención a lo estatuido en el inciso cuarto del Art. 38 de la Ley denominada Pascua. Tal inciso, como se indicó, solo permitía entregar en concesión de explotación a la Corporación de Fomento de la Producción o a alguna de sus empresas o sociedades filiales, a instituciones fiscales, semifiscales y de administración autónoma, a empresas o entidades en que tenga intervención el Fisco por aporte de capital y a los servicios de utilidad pública, no siendo posible que el Fisco transfiriera el dominio de dicho territorio, dado que la Ley lo único que autorizaba era la en concesión de explotación a las instituciones que dicho artículo e inciso enumeraban. 
Así las cosas, en contravención de Ley, la Comisión Especial de Radicaciones autorizó a CORFO para transferir el dominio de dichos terrenos a don Hugo Salas Román, quien no cumplía con las exigencias del D.L. 2.885, suscribiéndose el 27 de enero de 1981 la escritura pública de Compraventa del Hotel Hana Roa, entre CORFO y el Sr. Salas Román, por el precio de \$31.000.000. Anotamos contra ley o en contravención de esta, dado el Decreto Ley No 2.885 del año 1979, que establece Normas Sobre el Otorgamiento de Títulos de Dominio y de Administración de Terrenos Fiscales en Isla de Pascua, del Ministerio de Tierras y Colonización, que en su artículo primero facultaba al Presidente de la República para otorgar títulos gratuitos de dominio en terrenos fiscales de Isla de Pascua, de conformidad con dicho cuerpo legal, reservando el derecho a solicitar dichos títulos solo o exclusivamente a los pascuenses o a los chilenos originarios o hijos de originarios de la Isla de Pascua, consagrando de esta forma, al igual que el ya tantas veces referido Acuerdo de Voluntades, el principio de ius sanguinis, en relación a la propiedad de los territorios que comprende Rapa Nui.

A principios de la última década del siglo pasado, el Sr. Salas Román aporta en dominio el predio y las instalaciones del Hotel Hana Roa a la Sociedad Hotelera Interamericana, en pago de acciones emitidas con fecha 30 de marzo de 1990, sociedad que pasa a estar en control de sus actuales titulares el año 2005, quienes en conocimiento de las irregularidades que llevaron a considerar al Sr. Salas como propietario de dichos terrenos no dudan en adquirir esa sociedad a fin de consolidar el despojo de que hoy son víctimas los integrantes del Clan Hito Rangi. De esta manera, burlan además con esta adquisición societaria el espíritu de la Ley No 19.253, denominada también Ley Indígena, la cual, en su Art. 69 de la Ley 19.253, impide la transferencia de tierras de Isla de Pascua a quienes no sean miembros del pueblo rapanui.

Son estas serie de irregularidades las que llevaron a los Hito Rangi a utilizar la autotutela como mecanismo de solución del conflicto anotado, mecanismo que el Derecho Internacional acepta como medio de resolución de conflicto en pueblos colonizados: el derecho a revelarse en contra de Leyes injustas impuestas por Estados foráneos en contra de pueblos que son oprimidos. Con mucha mayor razón, este derecho de autotutela se reivindica exponencialmente cuando las leyes del estado colonizador no son aplicadas en su cuerpo y espíritu, en tanto favorecen a los colonizados.

Aquí es menester hacer un paréntesis, dado que resulta fuerte para cualquier ciudadano chileno hablar de "pueblo colonizado" para referirse al rapanui. Sin embargo, el pueblo rapanui, técnicamente, sí lo es. Así, ignoro, y no es materia de este artículo, dilucidar cómo debe enfrentar dicha nación su forma de relacionarse con Chile, pero lo que sí es necesario destacar es que es el pueblo rapanui quien debe determinar, de acuerdo a los mecanismos que establezca, la forma de relacionarse con Chile o con otras naciones. Es por eso que no debemos olvidar, y en esto adscribo completamente la tesis de mi distinguido colega Rodrigo Gómez Segura, que el fenómeno colonizador chileno en la Polinesia es contemporáneo, y por ende ilegítimo, dado que esta suerte de asociación que se vislumbra en el Acuerdo de Voluntades no produjo más efectos que la ocupación militar-policial por parte de la Armada de Chile. Cuando esa ocupación cesa da lugar a un proceso de colonización efectiva de Te Pito o Te Henua, con la promulgación de la 
Ley Pascua en el año 1966. A partir de esa ley se crea el Departamento de Isla de Pascua y se concreta en definitiva la vigencia del Estado de Derecho Nacional en Isla de Pascua, en la que hasta dicha fecha operaba solo una jurisdicción militar de connotación naval. No debemos olvidar que más de un rapanui -algunos de ellos vivos- prefirieron huir de Isla de Pascua, embarcándose en rudimentarias embarcaciones para así no sufrir los atropellos clásicos de una ocupación militar que quebrantaba todos sus derechos.

Retomando la línea argumentativa expuesta hasta el momento, cabe destacar que, viéndose agotada la vía política-administrativa -la cual a juicio de quien escribe es la más idónea para solucionar la presente cuestión-, la familia Hito opta, como ya se indicó, por la autotutela de sus derechos violentados por décadas por un Estado indiferente, que en vez de operar por la justicia material lo hace por la formal, dándole más valor a una cadena "ininterrumpida de transferencias de 30 años" que a los derechos territoriales ancestrales del clan, los que pueden ser rastreados a lo menos por siete generaciones. Este Estado ya ha dejado de ser indiferente y se ha abanderizado inexplicablemente a favor de un conglomerado empresarial.

Para la anterior afirmación, baste recordar al Sr. Ministro del Interior, flanqueado por la representante visible de los controladores del Hotel Hana Roa, doña Jeannette Schess, y además por un senador, agradeciendo "la infinita generosidad de dicha familia", dado que los mismos, en forma unilateral, manifestaron su intención de restituir los terrenos en que emplazaron su hotel a la comunidad de Rapa Nui. Esto, por supuesto, una vez recuperada su inversión y por intermedio de una fundación o comunidad indígena, obviando nuevamente la costumbre rapanui y sus mecanismos o formas de propiedad.

El ministro pronunció esa frase por cuanto los rapanui, como pueblo, reconocen los derechos de propiedad que les asiste al clan Hito Rangi sobre los territorios en que se emplaza el Hotel Hana Roa, amén de que resulta dudoso, o al menos controversial, que se pretenda incorporar como directores de dicha Fundación o Comunidad a quienes autorizaron y/o aprobaron el proyecto del denominado hotel, especialmente si todos ellos sabían que la transferencia que se hizo de dichos terrenos al Sr. Salas era ilegal. Esta aclaración unilateral, que fue asumida como única alternativa mediática posible para salvar el desprestigio global que generan alternativas económicas no sustentables desde una perspectiva étnica, no es menor que una apuesta de turismo de étnico como la que pretende generar el Hotel Hana Roa, en abierto conflicto con miembros del pueblo y del cual pretenden valerse para generar dicha opción, la que a estas alturas resulta absolutamente inviable.

En fin, la Hotelera Panamericana pensó que invertir U\$ 50 millones bastaría para doblegar la voluntad de una tremenda familia, la cual se preparó emocional e intelectualmente para el gran paso que concretaría el día 1 de Agosto de 2010, cuando comienzan los actos de recuperación territorial de la familia Hito al ingresar a sus territorios ancestrales que injustamente le fueron despojados hace cuatro décadas.

De modo que nadie pensó que un grupo de pascuenses iban a ser capaces de alterar su destino mediante una inquebrantable voluntad, la cual no se ha dejado seducir por el dinero -io quién lee este artículo cree que no existieron ofrecimientos económicos en favor de la familia Hito mediante los cuales se intentó doblegar dicha movilización?-. 
Su movilización no fue quebrantada por el dinero, pero sí lo fue, momentáneamente, por el ente persecutor y por la policía, quienes, pese a existir dos resoluciones judiciales que no autorizaban el ingreso de agentes ejecutores al domicilio de mis representados, lo allanaron ilegalmente, deteniendo a dos miembros de dicho clan en abierta infracción de las normas que el nuevo código de enjuiciamiento criminal contempla y, lo que es aún peor, valiéndose de vehículos de la controladora del Hotel Hana Roa para transportar a los funcionarios policiales que realizaron dichas diligencias arbitrarias e ilegales, situación que fue oportunamente denunciada ante el Ministerio Público y que se encuentra en etapa de investigación desformalizada.

Son este cúmulo de antecedentes los que nos llevan a preguntarnos legítimamente qué espera el Gobierno para intervenir; la solución está en sus manos, la expropiación como alternativa constitucional aparece como razonable para dar una solución jurídica, económica y política a la encrucijada que hemos planteado... ¿Qué espera el Gobierno? Finalmente, como alguna vez escuché, no me cabe duda que los rapanui están dispuestos a morir por su causa. 